\title{
Environmental conditions and habitat characteristics influence trap and video detection probabilities for reef fish species
}

\author{
Nathan M. Bacheler ${ }^{1, *}$, David J. Berrane ${ }^{1}$, Warren A. Mitchell ${ }^{1}$, \\ Christina M. Schobernd ${ }^{1}$, Zebulon H. Schobernd ${ }^{1}$, Bradford Z. Teer ${ }^{1}$, \\ Joseph C. Ballenger ${ }^{2}$
}

\begin{abstract}
${ }^{1}$ National Marine Fisheries Service, Southeast Fisheries Science Center, 101 Pivers Island Road, Beaufort, NC 28516, USA
${ }^{2}$ Marine Resources Research Institute, South Carolina Department of Natural Resources, 217 Fort Johnson Road, Charleston, SC 29412, USA
\end{abstract}

\begin{abstract}
Monitoring programs often collect presence-absence data to understand range expansions or contractions, metapopulation dynamics, alien species invasions, or spatial and temporal trends in relative abundance. Using the proportion of sites occupied by a species is misleading, however, if surveys routinely fail to detect species that are present. We used chevron traps paired with underwater videos $(\mathrm{N}=1555)$ in a binomial (presence-absence) generalized additive modeling framework to quantify how environmental conditions, habitat characteristics, and the number of individuals at each site (i.e. site abundance) influenced the detection probabilities of economically important reef fish species in the southeastern USA. After accounting for variable site abundance, trap detection probabilities declined $40 \%$ for red porgy Pagrus pagrus, $65 \%$ for gray triggerfish Balistes capriscus, and $75 \%$ for vermilion snapper Rhomboplites aurorubens as percent hard bottom increased from 0 to $100 \%$. Increasing water temperature caused red porgy trap detection probability to decline modestly, while for gray triggerfish and vermilion snapper it increased substantially. Underwater video was more likely to detect black sea bass Centropristis striata, red porgy, and gray triggerfish when site abundance and water clarity were high and the video camera was facing downcurrent. Using multiple gears simultaneously, we quantified the ways in which predictor variables influenced the sampling process, which will help in designing surveys that maximize detection probability. Our results also suggest that pairing video cameras to trawls, fisheries acoustics, or nets allows for the estimation of detection probabilities.
\end{abstract}

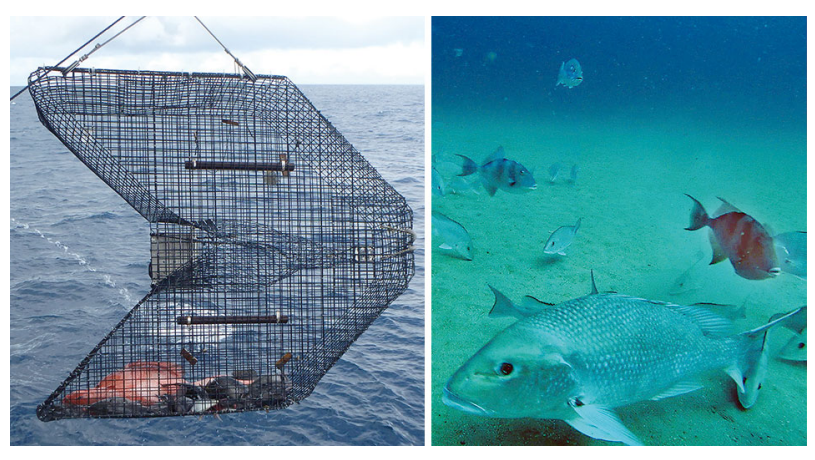

Adding video cameras to fish traps can enable estimation of reef fish detection probabilities for each gear.

Photos: Paul Ritter (left) and SEFSC, NOAA (right)

KEY WORDS: Detectability - Habitat - Catchability · Survey - GAM - Occupancy · Fishery-independent · Sampling gears

Resale or republication not permitted without written consent of the publisher

\section{INTRODUCTION}

Monitoring survey programs provide valuable ecosystem information such as data on spatial and temporal trends in abundance that inform, for instance, marine spatial planning and adaptive management (Halpern et al. 2008). The state variables in monitoring programs are typically abundance, relative abundance, or density, but estimating these variables is difficult and costly (Pollock et al. 2002) and may not 
be appropriate for rare or elusive species (Thompson 2004). Moreover, capture probability is nearly always assumed to be constant across space, time, habitat types, or environmental conditions, an assumption that is often unverified or incorrect (Hangsleben et al. 2013).

A lower-cost state variable often used instead of abundance or density is the occupancy rate of a species, defined as the proportion of sampling units occupied by a species, or sometimes the probability of presence within a sampling unit. It is based on the patterns of a species' presence or absence across a landscape or over time (MacKenzie et al. 2006). Information on the occupancy rates of species is particularly useful for understanding range expansion and contraction (Bartolino et al. 2011), metapopulation dynamics (Hanski 1999), and invasions by alien species (Reshetnikov \& Ficetola 2011). Occupancy rates are also used as a surrogate for population size or species abundance, especially at large spatial scales and for cryptic, rare, or territorial species (MacKenzie 2005).

Occupancy rates are misleading, however, if surveys fail to detect species that are truly present at a site (Monk 2014). It is essential to discriminate between true absence of a species at a site (i.e. structural zeroes) and the survey simply missing the species (i.e. sampling zeroes; MacKenzie et al. 2006). Not properly accounting for sampling zeroes (i.e. imperfect detection probability) leads to underestimated occupancy rates, biased habitat assessments, flawed management decisions, and possibly significant ecological and economic losses (Tyre et al. 2003).

Various approaches are used to estimate, or explicitly account for detection probability, including markrecapture, distance sampling, removal techniques, and occupancy modeling approaches. Each can be used to estimate detection probabilities, and thus provide better estimates of occupancy rates (see review by Katsanevakis et al. 2012). Although methodologies that account for imperfect detection are frequently used in wildlife studies, rarely are they employed to study fish species (MacKenzie et al. 2002, Rota et al. 2009). When carefully applied to marine fish species, however, methods accounting for imperfect detection have helped improve our understanding of sampling biases and the drivers of fish occupancy rates (Issaris et al. 2012, Coggins et al. 2014).

Here we use a novel paired sampling gear approach (i.e. fish traps with attached underwater video cameras) in a binomial modeling framework to relate the detection probabilities of 5 reef fish species to envi- ronmental conditions, habitat characteristics, and relative abundance along the Southeast Atlantic coast of the USA (SEUS). These species are targets of various fisheries in the region, and their management could be improved with a better understanding of how the fishery-independent sampling process might be influenced by predictor variables. If we ignore imperfect detection, then scientific inferences only pertain to the portion of the population available to sampling, not the total population (Pollock et al. 2004).

\section{MATERIALS AND METHODS}

\section{Study area}

We used fishery-independent chevron trap and underwater video data from the Southeast Reef Fish Survey (SERFS) to determine which variables influenced detection probabilities for various reef fish species in the SEUS (Fig. 1). We used 2011-2012 SERFS data in our analyses, a time when underwater video cameras were attached to traps deployed throughout the study area between North Carolina and Florida (Fig. 1).

The SERFS survey is designed to sample reef fish species and therefore targets hard substrate on the continental shelf and shelf-break, the preferred habitat of many economically important reef fish species in the region (Schobernd \& Sedberry 2009). The continental shelf and shelf-break in the SEUS are dominated by sand and mud substrates, but reef fish species associate with scattered patches of hard, rocky substrate (Kendall et al. 2008). Hard-bottom habitats sampled in our study ranged in complexity from flat limestone pavement, sometimes covered with a sand or gravel veneer, to high-relief rocky ledges (Schobernd \& Sedberry 2009). Sampling occurred from approximately Cape Hatteras, North Carolina, to St. Lucie Inlet, Florida (Fig. 1).

\section{Sampling}

Stations were selected for sampling in 1 of 3 ways. (1) Most sites were randomly selected from the SERFS sampling frame that consisted of approximately 3000 stations on or near hard-bottom habitat. (2) Some stations in the sampling frame were sampled opportunistically even though they were not randomly selected for sampling in a given year. (3) New hard-bottom stations were added during 


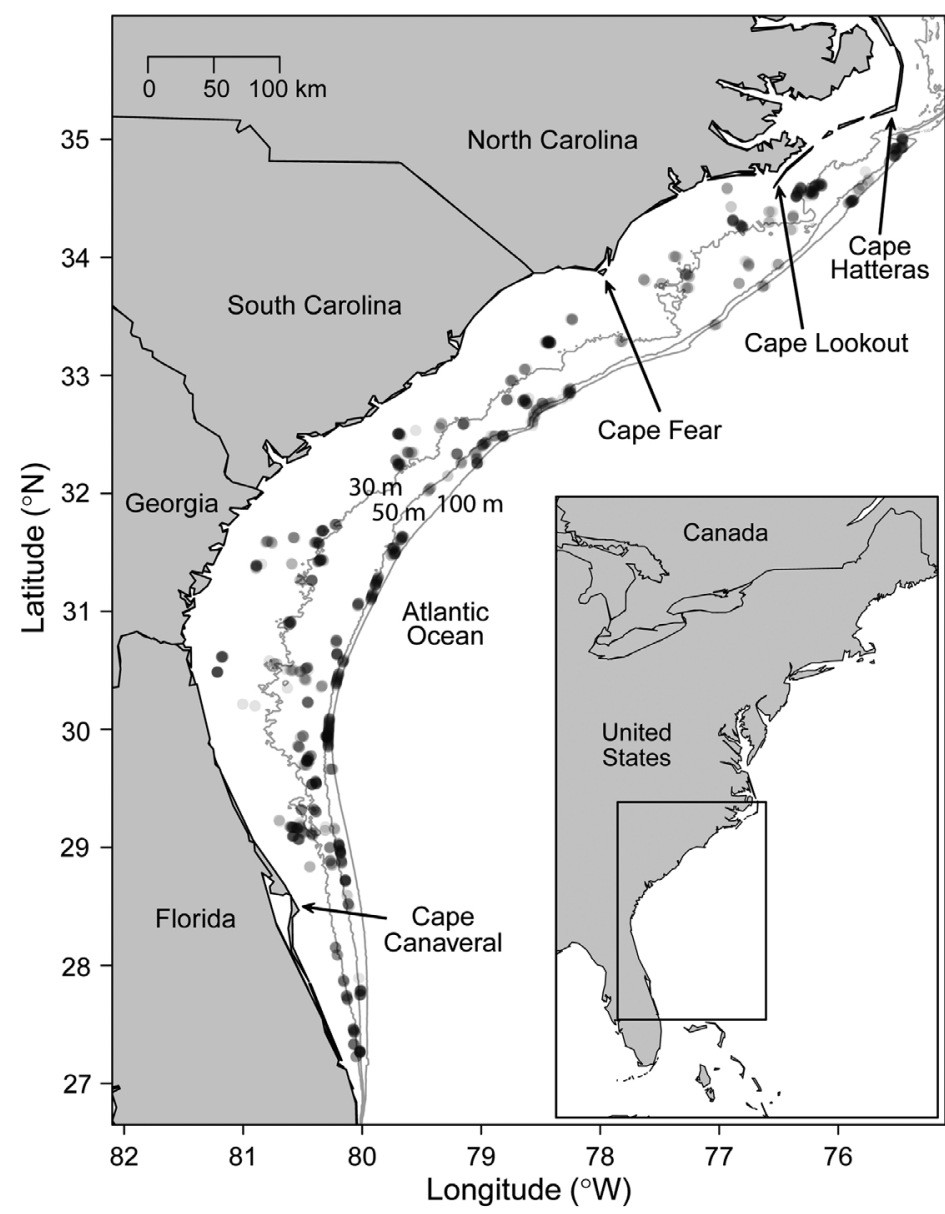

Fig. 1. Spatial distribution of chevron trap and video sampling by the Southeast Reef Fish Survey between North Carolina and Florida, USA, in 2011 and 2012. Each dot represents a trap-video deployment included in the analysis; the darker the symbol, the greater the overlap among points

the study period through the use of information from various sources including fishermen, charts, and historical surveys. These new locations were investigated using a vessel echosounder or drop cameras and sampled if hard bottom was detected. All sampling for this study occurred during daylight hours between April and October on the RV 'Savannah,' RV 'Palmetto,' or the NOAA Ship 'Pisces' using identical methodologies as described below.

Chevron traps were constructed from plastic-coated, galvanized $2 \mathrm{~mm}$ diameter wire $\left(\right.$ mesh size $\left.=3.4 \mathrm{~cm}^{2}\right)$ and measured $1.7 \mathrm{~m} \times 1.5 \mathrm{~m} \times 0.6 \mathrm{~m}$, with a total volume of $0.91 \mathrm{~m}^{3}$ (Fig. 2; see Bacheler et al. 2013a). Trap mouth openings were shaped like a teardrop and measured approximately $18 \mathrm{~cm}$ wide and $45 \mathrm{~cm}$ high. Each trap was baited with 24 menhaden (Brevoortia spp.). Traps were typically deployed in groups of 6 , and each trap in a set was deployed at least $200 \mathrm{~m}$ from all other traps in a given year to provide some measure of independence among traps. A soak time of $90 \mathrm{~min}$ was targeted for each trap deployed, and any trap not fishing properly (e.g. bouncing due to waves or current, trap mouth was obstructed) was excluded from analysis. All fish caught were enumerated and measured for total length.

A high-definition Canon® Vixia HFS-S200 video camera in a Gates underwater housing was attached over the mouth of each trap, facing away from the trap (Fig. 2). Canon cameras had a width of view of approximately $60^{\circ}$ and were used to identify and enumerate fish seen swimming around the trap and quantify microhabitat features. A second high-definition GoPro ${ }^{\circledR}$ Hero video or Nikon Coolpix S210/S220 still camera was attached over the nose of most traps in an underwater housing, and was used to quantify microhabitat features in the opposite direction. Traps with corresponding videos are hereafter referred to as 'trap-video samples.' Trap-video samples were excluded from our analysis if videos were unreadable for any reason (e.g. too dark, camera out of focus, files corrupt) or the traps did not fish properly.

Relative abundance of reef fish on video was estimated using the MeanCount approach (Schobernd et al. 2014), which was calculated as the mean number of individuals of each species over a number of video frames in the video sample. We limited our video reading time to an interval of

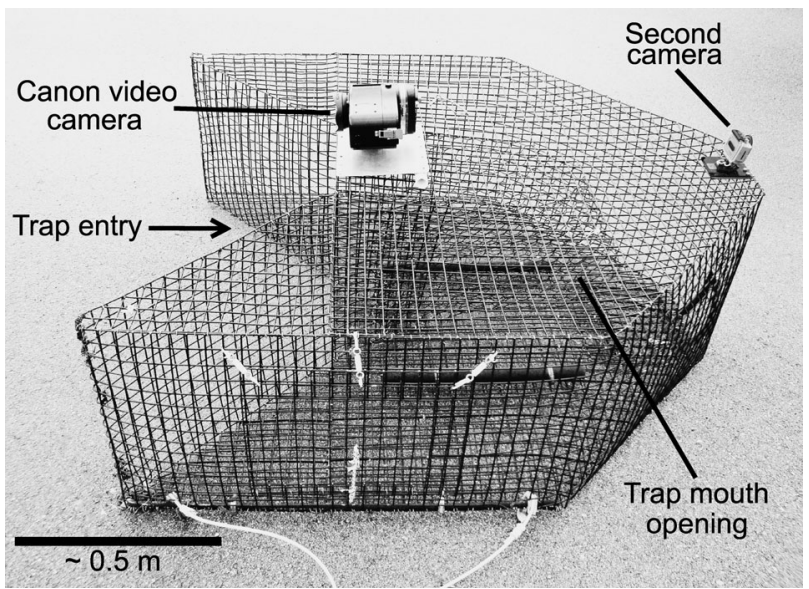

Fig. 2. Chevron trap fitted with 2 outward-looking cameras deployed by the Southeast Reef Fish Survey in 2011 and 2012. Videos from the Canon ${ }^{\circledR}$ Vixia HF S200 cameras were used for counting reef fish and recording habitat information, while the second camera (GoPro® Hero or Nikon Coolpix S210/S220) was only used for additional habitat description 
20 total minutes, commencing 10 min after the trap landed on the bottom to allow time for the trap to settle. We read $1 \mathrm{~s}$ snapshots every $30 \mathrm{~s}$ for the $20 \mathrm{~min}$ time interval, totaling 41 snapshots read for each video. The mean number of individuals for each target species in the 41 snapshots was considered the MeanCount for that species in each video sample. MeanCount was chosen because it tracks true abundance linearly (Schobernd et al. 2014), but 1 downside is that it is not $100 \%$ effective at documenting all species present at a site (Bacheler \& Shertzer 2015). Due to logistical constraints, we read videos for 107 fish species: (1) those listed in the Fish Stock Sustainability Index (NMFS 2014), (2) highly migratory species such as sharks, mackerels, and tunas, and (3) the invasive lionfish Pterois spp.

Substrate was visually estimated for each video as the percent of the bottom that consisted of hard, consolidated sediment at least $10 \mathrm{~cm}$ in diameter. Relief was estimated as the maximum relief of the substrate within the viewing area, classified as 'low' $(<0.3 \mathrm{~m})$, 'moderate' (0.3-1.0 m), or 'high' (>1.0 m). Biota were estimated as the total coverage of the substrate (\%) by attached biota such as algae, sponges, or soft corals, classified here as 'none' $(0 \%)$, 'low' (1-10\%), 'moderate' (11-40\%), or 'high' (>40\%). For each station sampled, estimates were generated for each of the 2 cameras, after which a mean was calculated; if the second camera did not record for any reason, habitat was scored from the Canon camera only. The maximum relief from either video was used for relief. Current direction was also estimated based on particle movements in relation to video camera field of view, and was classified as 'away,' 'sideways,' or 'towards'. Water clarity was classified as 'low' if substrate could not be seen, 'moderate' if substrate (but not horizon) could be seen, and 'high' if horizon could be seen in the distance. Bottom water temperature $\left({ }^{\circ} \mathrm{C}\right)$ was measured for each group of 6 simultaneously deployed traps using a 'conductivity-temperature-depth' cast, and depth $(\mathrm{m})$ was measured for each trap-video deployment. Samples with missing or unknown habitat, current, or temperature values were excluded from analysis, as were samples with soak times greater than 150 min due to low sample sizes.

\section{Data analysis}

Trap detection probability was estimated using only those trap-video samples where a reef species of interest was detected on the video (i.e. known to be present at the site); the presence or absence of that species in the concomitant traps was then used as the response variable in a binomial model and related to covariates. Likewise, video detection probability was determined by examining only those trap-video samples where the species was caught in the trap, and its presence or absence on the corresponding videos was also related to covariates.

Two criteria were used to determine whether a particular reef fish species could be included in the analysis using binomial models. (1) Initial models suggested that video (for trap detection probability models) or trap (for video detection probability models) frequency of occurrence needed to be at least 200 in order for models to converge. (2) Species were only included if they had raw trap or video detection probabilities between 0.10 and 0.90 ; models rarely converged (due to a lack of contrast) when detection probabilities were extremely high or extremely low. Using these criteria, red porgy Pagrus pagrus, gray triggerfish Balistes capriscus, vermilion snapper Rhomboplites aurorubens, and red snapper Lutjanus campechanus were included in the trap detection probability models, and the same species were included in the video detection probability models except that black sea bass Centropristis striata was included and red snapper was removed.

Binomial generalized additive models (GAMs) were used to relate the presence or absence of species to predictor variables. GAMs are generalized linear models, except that a component of each linear predictor is a sum of smooth (i.e. nonlinear) functions of the predictor variables in the model (Wood 2006). GAMs extend traditional additive models by allowing for alternative distributions of underlying random variation, just as generalized linear models allow for alternative distributions in linear models. The response variable for binomial models was the presence or absence of each reef fish species in traps or videos when the species was confirmed to be present at the site using the other (paired) sampling gear.

Prior to model development, we assessed whether the predictor variables included in binomial models exhibited multicollinearity, because its presence causes erratic model behavior and should be avoided (Neter et al. 1989). We quantified the severity of multicollinearity among predictor variables using the variance inflation factor (VIF), which measures the amount of variance that is inflated for each variable as a result of its collinearity with other predictor variables. The VIF for all predictor variables was less than 3.5, which is below the level generally acknowledged to be problematic (5-10; Neter et al. 1989). Furthermore, pairwise correlation plots among all 
predictor variables did not show any clear patterns, suggesting that no significant multicollinearity existed among predictor variables in our data set.

We included predictor variables in trap and video binomial models based on specific hypotheses and previous research. For trap detection, we included 7 predictor variables in binomial models. Current direction was included because we hypothesized that fish would be more likely to be caught when the mouth of the trap is facing downstream, as opposed to upstream, because of fish staying in the bait plume (Zhou \& Shirley 1997). Three habitat variables were included (i.e. percent of substrate that is hard bottom, attached biota coverage, maximum substrate relief) because some marine organisms have higher catch rates on soft, open sediments than rocky, high-relief substrate (Robichaud et al. 2000, Geraldi et al. 2009). Water temperature was included because physiological studies suggest that fish activity and feeding rates are temperature-dependent (Fry 1967); depth was not considered given its multicollinearity with temperature. Soak time of the trap was included because we hypothesized that fish species would be more likely to be detected in traps that soaked for longer periods of time. The video MeanCount index of abundance for the particular species of interest was also included in trap detection probability models to standardize for variable fish abundance around the trap; we hypothesized that fish species would be more likely to be detected when their site abundance was high.

The full binomial GAM relating trap detection probability to predictor variables was:

$$
\begin{aligned}
\eta= & \alpha+f_{1}(\text { cur })+f_{2}(\text { biota })+f_{3}(\text { relief })+s_{1}(\text { meancount }) \\
& +s_{2}(\text { temp })+s_{3}(\text { soak })+s_{4}(\text { substrate })
\end{aligned}
$$

where $\eta$ is the probability of presence in the trap when seen on the corresponding video, $\alpha$ is the intercept, cur is current direction, biota is the percent coverage of attached biota, relief is the maximum relief of the substrate, meancount is the log-transformed site-specific abundance for each species from video, temp is the bottom water temperature $\left({ }^{\circ} \mathrm{C}\right)$, soak is the soak time of the trap, substrate is the percent of the substrate that was hard bottom, $f_{1-3}$ are categorical functions, and $s_{1-4}$ are nonparametric smoothing functions.

Four predictor variables were considered for inclusion in video models. Water clarity was included because we expected fish to be detected by video more frequently when water was clear than when it was turbid. Current direction was included because we hypothesized that fish would tend to be detected more often when the camera was facing downstream compared to upstream because of the bait plume from the trap. Maximum substrate relief was included to control for the possibility that fish might be more likely to be obscured (and detected less frequently) in high-relief habitats compared to flat substrate. Last, we included trap catch to standardize for variable relative abundance at a site.

The full binomial GAM model relating video detection probability to predictor variables was:

$\eta=\alpha+f_{1}($ clarity $)+f_{2}($ cur $)+f_{3}($ relief $)+s_{1}($ trap catch $)$

where $\eta$ is the probability of presence on a video when caught in the corresponding trap, $\alpha$ is the intercept, clarity is water clarity, cur is current direction, relief is the maximum relief of the substrate, trap catch is the log-transformed site-specific trap catch of each species, $f_{1-3}$ are categorical functions, and $s_{1}$ is a nonparametric smoothing function.

For each model developed for each species and gear combination, we compared full GAMs to various reduced models that contained fewer predictor variables. Comparisons were made using the unbiased risk estimator (UBRE) and Akaike's information criterion (AIC) scores (Burnham \& Anderson 2002). For each method, the model with the lowest UBRE and AIC scores was considered to be the most parsimonious and was selected as the best model in that particular model set. In all cases, residuals in final models met assumptions of normality and constant variance. All models were coded and analyzed in $\mathrm{R}$ version 3.0 ( $\mathrm{R}$ Core Team 2014) using the mgcv library, version 1.7-22 (Wood 2011). There were also no consistent patterns in the relationship between the semivariance of the model residuals and distance between sampling points, indicating negligible spatial autocorrelation in the residuals.

The overall influence of predictor variables on trap or video detection probability was visualized using a bootstrapping approach. We resampled the predictions $(\mathrm{N}=10000)$ for each model at mean values of all predictor variables according to the point-wise estimates of error that were assumed to be normally distributed. Since mean values did not exist for categorical data, the following levels were used to predict detection probabilities: current direction of 'away,' attached biota coverage of 'low,' substrate relief of 'low,' and water clarity of 'moderate.' The exact values or levels chosen for prediction influenced the absolute estimates of detection probability, but not the relative pattern (our primary focus). All $95 \%$ confidence intervals were estimated as the 0.025 and 0.975 quantiles of the 10000 point estimates. 


\section{RESULTS}

In total, 1555 trap-video samples were included in our analysis. More samples were included from 2012 than 2011, but the dates, latitudes, depths, and bottom water temperatures were similar between the 2 years (Table 1$)$.

\section{Trap detection probability}

Red porgy had the highest video frequency of occurrence, followed by gray triggerfish, vermilion snapper, and red snapper (Table 2). Considering only those trap-video samples when the target species was present on video, trap frequency of occurrence and trap detection probability were highest for red porgy and lowest for red snapper (Table 2).

Based on UBRE and AIC scores, models for all 4 fish species included video MeanCount, 3 species included temperature and substrate, 2 species included biota, and only a single species each included current direction, substrate relief, and soak time (Table 3 ). The relationship between trap detection probability and log-transformed video MeanCount was linear or slightly nonlinear for all species, indicating that all species were more likely to be caught in traps when more individuals were seen on video (Fig. 3).

Table 1. Annual Southeast Reef Fish Survey sampling information for video and trap samples included in binomial generalized additive models

\begin{tabular}{|lcc|}
\hline Variable & 2011 & 2012 \\
\hline Number of samples & 522 & 1033 \\
considered & & \\
Date range & 19 May-25 Oct & 24 Apr-10 Oct \\
Latitude range $\left({ }^{\circ} \mathrm{N}\right)$ & $27.2-34.3$ & $27.2-35.0$ \\
Depth range $(\mathrm{m})$ & $15-93$ & $15-106$ \\
Bottom temperature $\left({ }^{\circ} \mathrm{C}\right)$ & $14.8-28.8$ & $12.9-27.8$ \\
\hline
\end{tabular}

After accounting for variable site abundance of fish around traps, mean trap detection probability for red porgy, gray triggerfish, and vermilion snapper declined nearly linearly as the percent hard bottom increased (Fig. 4). For instance, mean trap detection probability of red porgy declined $40 \%$ as percent hard bottom increased from 0 to $100 \%$ (Fig. 4). Declines in mean trap detection probability for gray triggerfish (65\%) and vermilion snapper (75\%) over the same range in percent hard bottom were even more severe (Fig. 4).:

Trap detection probability for 3 reef fish species was also influenced by water temperature (Fig. 5). Mean trap detection probability for red porgy declined $16 \%$ as water temperature increased from 13 to $21^{\circ} \mathrm{C}$, but then plateaued at warmer water temperatures (Fig. 5). Gray triggerfish trap detection probability increased nearly linearly (233\%) as water temperature increased from 13 to $29^{\circ} \mathrm{C}$ (Fig. 5). Vermilion snapper trap detection probability was invariant to water temperature below $20^{\circ} \mathrm{C}$, but was positively related to temperature above $20^{\circ} \mathrm{C}$ (Fig. 5).

Three additional predictor variables had mixed effects on reef fish detection probabilities. As the coverage of attached biota increased at a site, mean trap detection probability for red porgy declined by $24 \%$ (Fig. 6). In contrast, trap detection probability of vermilion snapper was more variable but tended to increase with higher amounts of attached biota (Fig. 6). Mean trap detection probability was also slightly higher for red snapper at moderate substrate relief compared to low or high relief, while vermilion snapper were marginally more likely to be detected by traps at moderate soak times ( 100 min) than shorter or longer soak times.

\section{Video detection probability}

Black sea bass had the highest trap frequency of occurrence, followed by red porgy, gray triggerfish,

Table 2. Reef fish species sampled by the Southeast Reef Fish Survey between North Carolina and Florida, USA, in 2011 and 2012. In total, 1555 trap-video samples were included in the analysis

\begin{tabular}{|lcccc|}
\hline Species & $\begin{array}{c}\text { Frequency of } \\
\text { occurrence on video }\end{array}$ & $\begin{array}{c}\text { \% frequency of } \\
\text { occurrence on video }\end{array}$ & $\begin{array}{c}\text { Trap frequency of occur- } \\
\text { rence when seen on video }\end{array}$ & $\begin{array}{c}\text { Overall trap } \\
\text { detection probability }\end{array}$ \\
\hline Red porgy & 661 & 0.43 & 390 & 0.59 \\
Gray triggerfish & 475 & 0.32 & 240 & 0.51 \\
Vermilion snapper & 436 & 0.28 & 205 & 0.47 \\
Red snapper & 383 & 0.25 & 146 & 0.38 \\
\hline
\end{tabular}


Table 3. Binomial generalized additive models of reef fish species presence or absence in traps when seen on corresponding videos collected by the Southeast Reef Fish Survey. Estimated degrees of freedom are shown for each term; asterisks denote significance at the following alpha levels: ${ }^{*}=0.10,{ }^{* *}=0.05,{ }^{* * *} 0.01$; ex: covariate was excluded from that particular model; UBRE: unbiased risk estimator score; AIC: Akaike's information criterion. Base model given in Eq. (1). Only the 4 best models are shown for each species, based on UBRE and AIC scores

\begin{tabular}{|c|c|c|c|c|c|c|c|c|c|}
\hline Model (Base minus covariates) & UBRE & AIC & $f_{1}($ cur $)$ & $f_{2}($ biota $)$ & $f_{3}($ relief $)$ & $s_{1}($ meancount $)$ & $s_{2}(t e m p)$ & $S_{3}($ soak $)$ & $s_{4}($ substrate $)$ \\
\hline \multicolumn{10}{|l|}{ Red porgy } \\
\hline Base - relief - soak & 0.1826 & 781.67 & $2^{* *}$ & $3^{* *}$ & ex & $1.0^{* * *}$ & $2.3^{*}$ & ex & $1.0^{* * *}$ \\
\hline Base - soak & 0.1832 & 782.08 & $2^{* *}$ & $3^{* *}$ & 2 & $1.0^{* * *}$ & $2.3^{*}$ & ex & $1.0^{*}$ \\
\hline Base - relief & 0.1856 & 783.66 & $2^{* *}$ & $3^{* *}$ & ex & $1.0^{* * *}$ & $2.3^{*}$ & 1.0 & $1.0^{* * *}$ \\
\hline Base & 0.1862 & 784.06 & $2^{* *}$ & $3^{* *}$ & 2 & $1.0^{* * *}$ & $2.3^{*}$ & 1.0 & $1.0^{*}$ \\
\hline \multicolumn{10}{|l|}{ Gray triggerfish } \\
\hline Base - cur - biota - soak - relief & 0.2719 & 604.14 & ex & ex & ex & $1.2^{* * *}$ & $1.0^{* * *}$ & ex & $1.8^{* *}$ \\
\hline Base - cur - biota - soak & 0.2730 & 604.69 & ex & ex & 2 & $1.0^{* * *}$ & $1.0^{* * *}$ & ex & $1.5^{* * *}$ \\
\hline Base - cur - biota - relief & 0.2734 & 604.86 & ex & ex & ex & $1.3^{* * *}$ & $1.0^{* * *}$ & 1.0 & $1.8^{* *}$ \\
\hline Base - cur - biota & 0.2750 & 605.62 & ex & ex & 2 & $1.0^{* * *}$ & $1.0^{* * *}$ & 1.0 & $1.5^{* *}$ \\
\hline \multicolumn{10}{|l|}{ Vermilion snapper } \\
\hline Base - cur - relief & 0.2090 & 527.13 & ex & $3^{* * *}$ & ex & $5.3^{* * *}$ & $2.8^{* * *}$ & $1.8^{*}$ & $1.0^{* * *}$ \\
\hline Base - cur - relief - soak & 0.2131 & 528.90 & ex & $3^{* * *}$ & ex & $5.4^{* * *}$ & $2.6^{* * *}$ & ex & $1.0^{* * *}$ \\
\hline Base - cur & 0.2142 & 529.40 & ex & $3^{* * *}$ & 2 & $5.5^{* * *}$ & $2.8^{* * *}$ & $1.8^{*}$ & $1.0^{* * *}$ \\
\hline Base - relief & 0.2177 & 530.92 & 2 & $3^{* * *}$ & ex & $5.3^{* * *}$ & $2.7^{* * *}$ & $1.8^{*}$ & $1.0^{* * *}$ \\
\hline \multicolumn{10}{|l|}{ Red snapper } \\
\hline Base - cur - biota - temp - soak - substrate & 0.2354 & 473.16 & ex & ex & $2^{*}$ & $1.0^{* * *}$ & ex & ex & ex \\
\hline Base - cur - biota - temp - soak & 0.2358 & 473.31 & ex & ex & $2^{*}$ & $1.0^{* * *}$ & ex & ex & 5.5 \\
\hline Base - cur - biota - temp & 0.2394 & 474.70 & ex & ex & $2^{*}$ & $1.0^{* * *}$ & ex & 1.0 & 5.5 \\
\hline Base - cur - biota - temp - substrate & 0.2399 & 474.89 & ex & ex & 2 & $1.0^{* * *}$ & ex & 1.0 & ex \\
\hline
\end{tabular}

and vermilion snapper (Table 4). Considering only those trap-video samples where the target species was caught in the trap, video detection probability was highest for red porgy and lowest for black sea bass.

Based on UBRE and AIC, the best binomial GAMs for video detection probability were similar for black sea bass, red porgy, and gray triggerfish in that they included all 4 predictor variables: water clarity, current direction, substrate relief, and trap catch (Table 5). Unlike the other 3 species, the model for vermilion snapper only included trap catch (Table 5).

Video detection probability for all 4 reef fish species examined was positively related to their logtransformed catch in corresponding traps (Fig. 7). Mean video detection probability of black sea bass increased strongly and linearly at low levels of logtransformed trap catch, but reached an asymptote at higher levels of trap catch (Fig. 7). Mean video detection probability for red porgy, gray triggerfish, and vermilion snapper were nearly linearly related to their own log-transformed trap catch, suggesting that video was more likely to detect these species when more individuals of each species were caught in the trap (Fig. 7).
After standardizing for variable abundance of each species at a site (by including trap catch as a predictor variable), mean video detection probabilities of black sea bass, red porgy, and gray triggerfish were significantly influenced by water clarity, current direction, and substrate relief (Fig. 8). All 3 reef fish species were less likely to be detected by video when water clarity decreased (Fig. 8). Likewise, all 3 species were more likely to be detected when the current direction was away from the camera as opposed to moving towards the camera. Mean video detection probabilities were also slightly higher for black sea bass, red porgy, and gray triggerfish at high compared to low relief substrate (Fig. 8).

\section{DISCUSSION}

The pattern of a species' presence or absence (i.e. occupancy) across a landscape is a critical ecological state variable that has been used to estimate abundance, understand range expansions or contractions, and elucidate metapopulation dynamics (MacKenzie 2005). However, not accounting for imperfect detection confounds occupancy data because missing a 

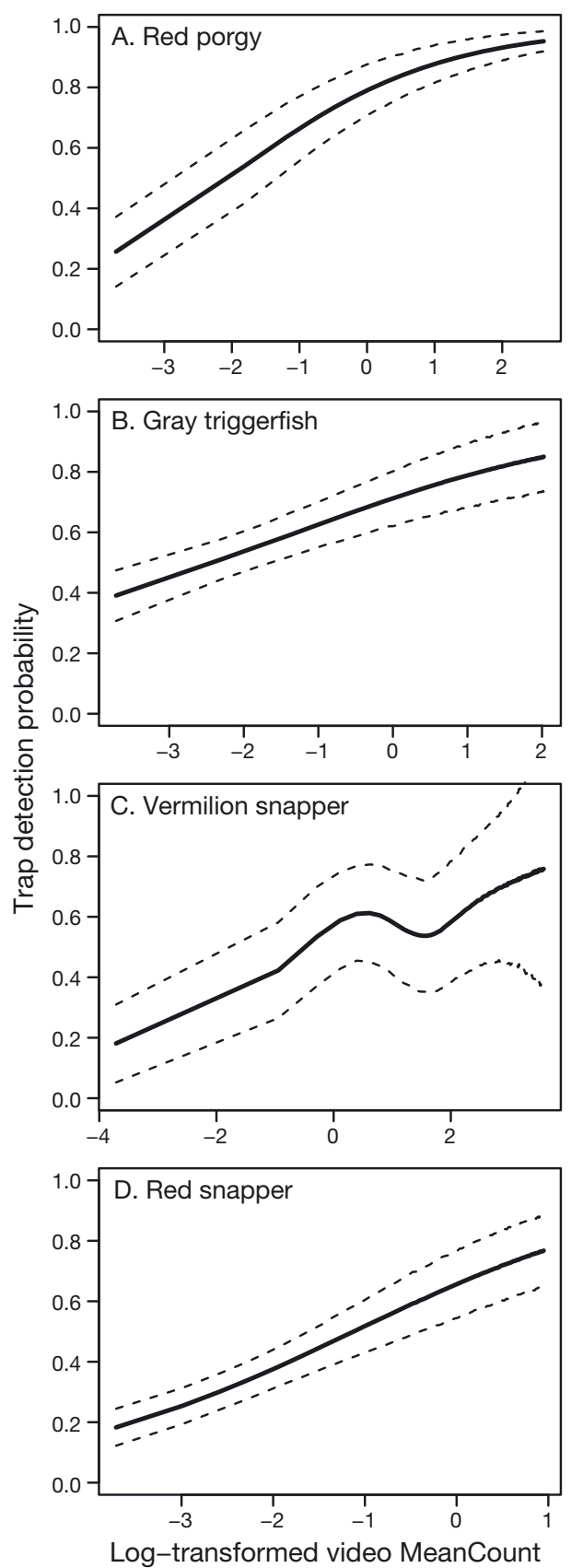

Fig. 3. Trap detection probability of 4 reef fish species related to their log-transformed video-based index of abundance (i.e. MeanCount) from Southeast Reef Fish Survey trap-video sampling. Solid lines are the predicted trap detection probabilities, and dashed lines are 95\% confidence intervals

species at a site ends up being treated as an absence from that site, leading to underestimated occupancy rates, biased habitat relationships, and potentially erroneous management recommendations (Tyre et al. 2003, MacKenzie et al. 2006). Imperfect detection also distorts our understanding of community struc-
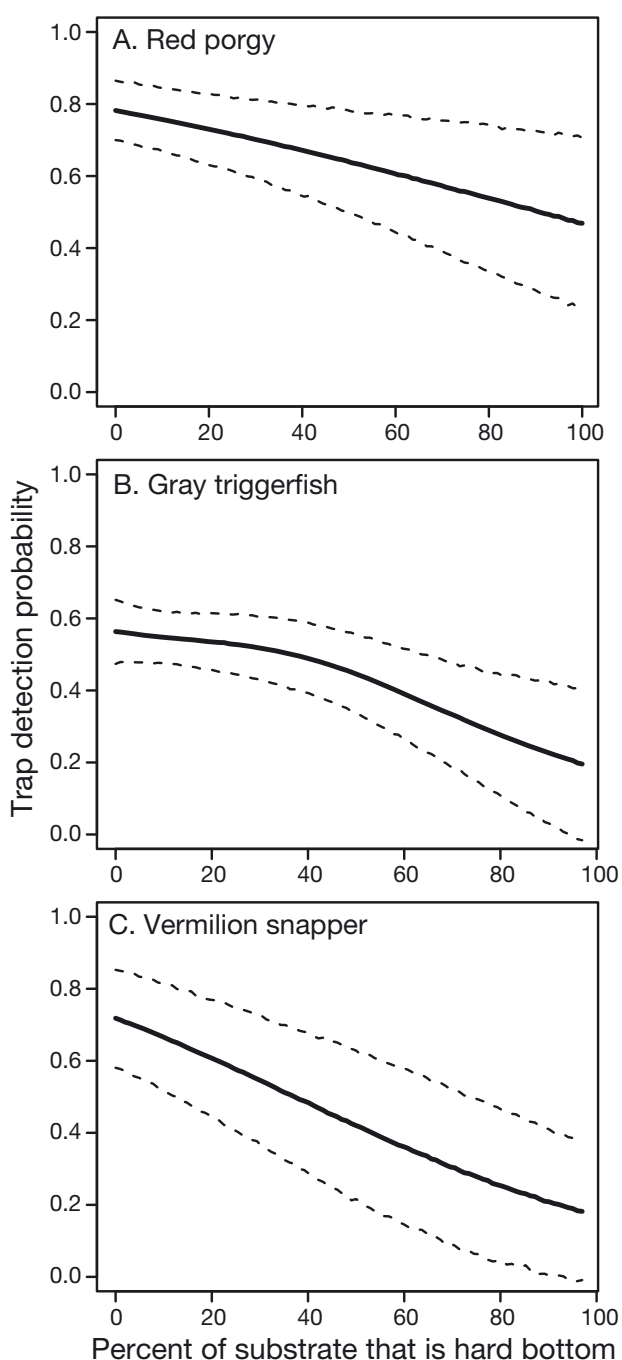

Fig. 4. Trap detection probability of 3 reef fish species related to the percent of substrate that is hard bottom from Southeast Reef Fish Survey trap-video sampling. Solid lines are the predicted trap detection probabilities, and dashed lines are $95 \%$ confidence intervals

ture and dynamics. We explicitly modeled detection probabilities for 5 reef fish species using a combined gear approach and spatially and temporally extensive sampling data to show that trap and video detection probabilities were influenced by environmental conditions, habitat characteristics, and site abundance of each target species. These results improve our understanding of the sampling process for reef fish species as well as the ecological dynamics of marine fish species by providing a novel method to remove biases in occupancy rates due to variable detection probabilities. They also provide general guidance to scientists interested in developing trap or video surveys for reef fish species, and could be particularly useful if targeting rare species. 

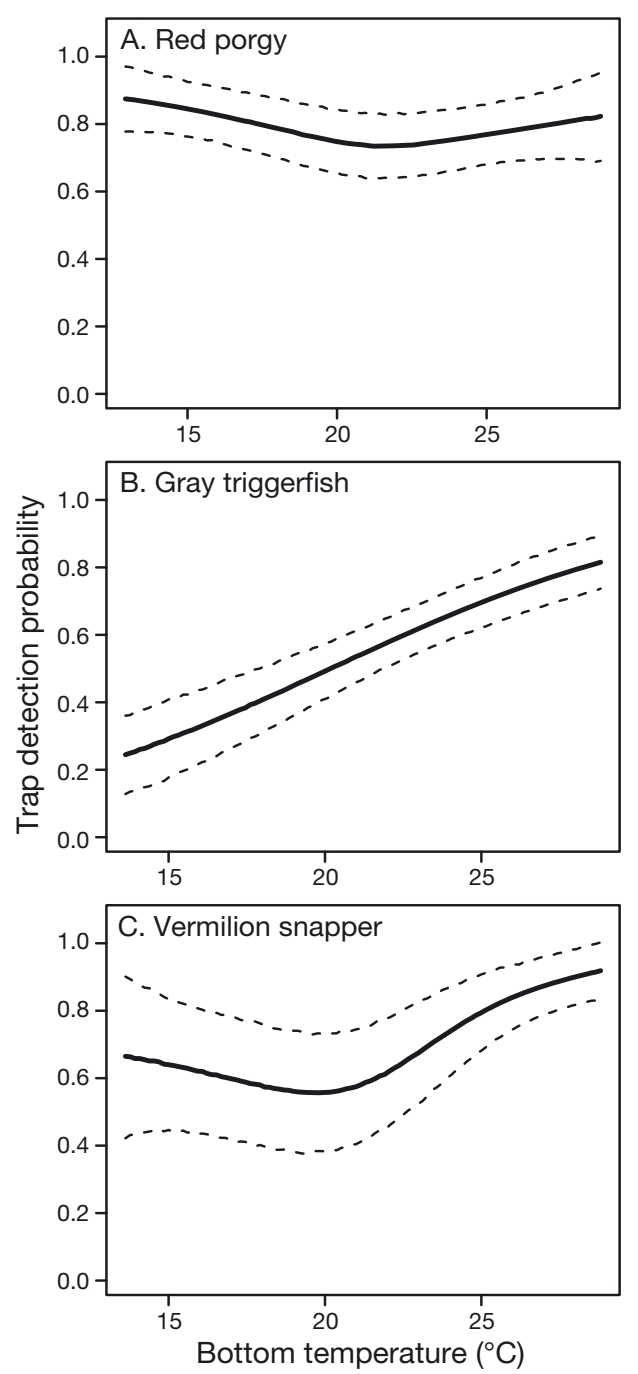

Fig. 5. Trap detection probability of 3 reef fish species related to the bottom water temperature $\left({ }^{\circ} \mathrm{C}\right)$ from Southeast Reef Fish Survey trap-video sampling. Solid lines are the predicted trap detection probabilities, and dashed lines are $95 \%$ confidence intervals

\section{Influence of habitat}

We found that red porgy, gray triggerfish, and vermilion snapper were all more likely to be detected by traps on soft-bottom compared to hard-bottom sub-

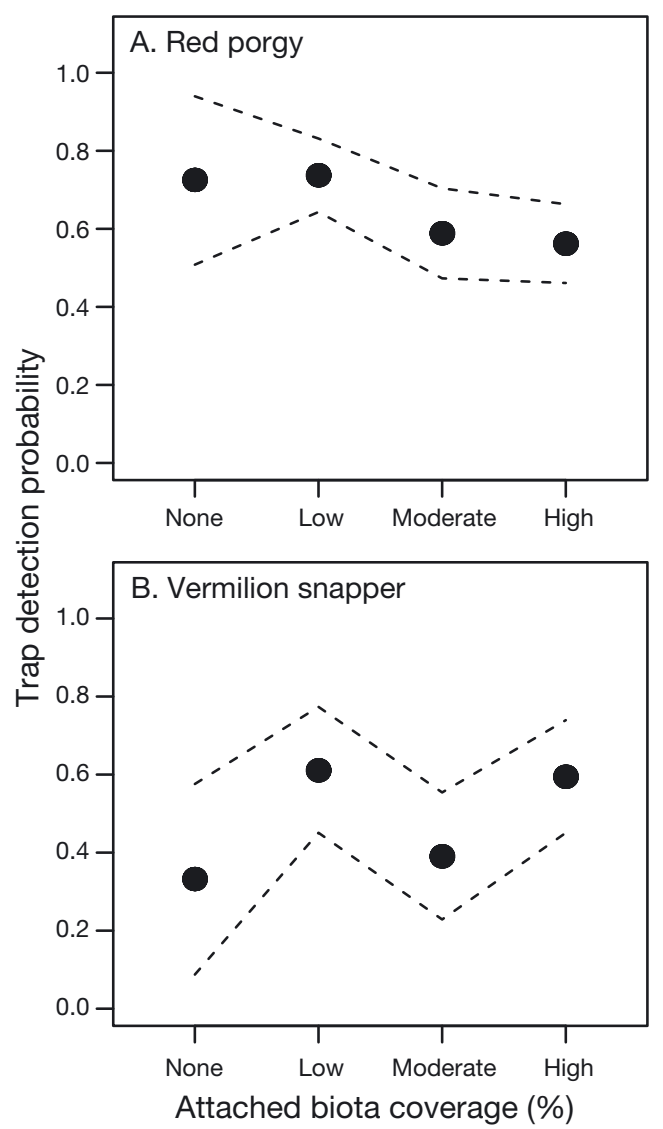

Fig. 6. Trap detection probability of 2 reef fish species related to percent coverage of attached biota (i.e. sponges, soft corals, algae) from Southeast Reef Fish Survey trap-video sampling. Filled circles are the predicted trap detection probabilities, and dashed lines are $95 \%$ confidence intervals

strate, while red snapper was not. Detectability of fish by various sampling gears is in some cases habitatdependent (Green et al. 2013). For instance, Geraldi et al. (2009) found that American lobster Homarus americanus abundance was higher on hard, rocky substrate, but catchability of individual lobsters was higher on soft (unstructured) substrate. American lobster movement rates were shown to be highest on soft substrate, suggesting that traps may have been encountered more often in that habitat type (Geraldi

Table 4. Species-specific trap and video information for the 4 reef fish species sampled by the Southeast Reef Fish Survey, used to determine video detection probability. In total, 1555 trap-video samples were included in the analysis

\begin{tabular}{|lcccc|}
\hline Species & $\begin{array}{c}\text { Frequency of } \\
\text { occurrence in traps }\end{array}$ & $\begin{array}{c}\text { \% frequency of } \\
\text { occurrence in traps }\end{array}$ & $\begin{array}{c}\text { Video frequency of occur- } \\
\text { rence when caught in trap }\end{array}$ & $\begin{array}{c}\text { Overall video } \\
\text { detection probability }\end{array}$ \\
\hline Black sea bass & 857 & 0.55 & 488 & 0.57 \\
Red porgy & 442 & 0.28 & 390 & 0.88 \\
Gray triggerfish & 381 & 0.25 & 240 & 0.63 \\
Vermilion snapper & 263 & 0.17 & 205 & 0.78 \\
\hline
\end{tabular}


Table 5. Binomial generalized additive models of reef fish species' presence or absence on videos when caught in corresponding traps by the Southeast Reef Fish Survey. Estimated degrees of freedom are shown for each term; asterisks denote significance at the following alpha levels: ${ }^{*}=0.10,^{* *}=0.05,{ }^{* * *} 0.01$; ex: covariate was excluded from that particular model; UBRE: unbiased risk estimator score; AIC: Akaike's information criterion. Base model given in Eq. (2). Only the 4 best models are shown for each species, based on UBRE and AIC scores

\begin{tabular}{|c|c|c|c|c|c|c|}
\hline $\begin{array}{l}\text { Model (Base minus } \\
\text { covariates) }\end{array}$ & UBRE & AIC & $f_{1}$ (clarity) & $f_{2}($ cur $)$ & $f_{3}($ relief $)$ & $s_{1}($ trap catch $)$ \\
\hline \multicolumn{7}{|l|}{ Black sea bass } \\
\hline Base & 0.0322 & 884.6 & $2^{* * *}$ & $2^{* * *}$ & $2^{* * *}$ & $1.0^{* * *}$ \\
\hline Base - clarity & 0.0549 & 904.1 & ex & $2^{* * *}$ & $2^{* * *}$ & $1.0^{* * *}$ \\
\hline Base - relief & 0.0573 & 906.1 & $2^{* * *}$ & $2^{* * *}$ & ex & $1.0^{* * *}$ \\
\hline Base - cur & 0.0951 & 938.5 & $2^{* * *}$ & ex & $2^{* * *}$ & $1.0^{* * *}$ \\
\hline \multicolumn{7}{|l|}{ Red porgy } \\
\hline Base & -0.3438 & 290.0 & $2^{* * *}$ & $2^{* *}$ & $2^{* * *}$ & $1.7^{* * *}$ \\
\hline Base - cur & -0.3352 & 293.8 & $2^{* * *}$ & ex & $2^{* * *}$ & $3.4^{* * *}$ \\
\hline Base - relief & -0.3347 & 294.1 & $2^{* * *}$ & $2^{* *}$ & ex & $1.4^{* * *}$ \\
\hline Base - clarity & -0.3276 & 297.2 & ex & $2^{*}$ & $2^{* * *}$ & $1.4^{* * *}$ \\
\hline \multicolumn{7}{|l|}{ Gray triggerfish } \\
\hline Base & 0.1954 & 455.4 & $2^{*}$ & $2^{* * *}$ & $2^{* *}$ & $1.8^{* * *}$ \\
\hline Base - clarity & 0.2001 & 457.2 & ex & $2^{* *}$ & $2^{* * *}$ & $1.8^{* * *}$ \\
\hline Base - relief & 0.2087 & 460.5 & $2^{* *}$ & $2^{* * *}$ & ex & $1.8^{* * *}$ \\
\hline Base - cur & 0.2135 & 462.3 & 2 & ex & $2^{* *}$ & $1.8^{* * *}$ \\
\hline \multicolumn{7}{|l|}{ Vermilion snapper } \\
\hline $\begin{array}{l}\text { Base - clarity - cur - } \\
\text { relief }\end{array}$ & 0.0079 & 265.1 & ex & ex & ex & $1.0^{* * *}$ \\
\hline Base - clarity - relief & 0.0110 & 265.9 & ex & 2 & ex & $1.0^{* * *}$ \\
\hline Base - clarity - cur & 0.0132 & 266.5 & ex & ex & 2 & $1.0^{* * *}$ \\
\hline Base - clarity & 0.0158 & 267.2 & ex & 2 & 2 & $1.0^{* * *}$ \\
\hline
\end{tabular}

attached biota increased, but the opposite relationship was observed for vermilion snapper, albeit with more variability. Robichaud et al. (2000) showed that although reef fish densities were higher in more complex habitats, reef fish catchability was lower, so that overall catch rates among habitats were similar. Underwater visual census methods also tend to miss more individuals in complex habitats (Green et al. 2013), similar to traps but via a different mechanism. Similar to the results of Green et al. (2013), we also expected to detect fish better on video in low-relief habitats, assuming that high-relief habitats may tend to obscure some fish on video. We found no evidence for this hypothesis, and in fact found some weak evidence that detectability for 3 out of 4 species was slightly higher in high-relief habitats. et al. 2009). It is also possible that scent plumes from bait in traps attenuated less rapidly in soft-bottom habitats, providing a stronger attraction than traps in rocky habitats (Tremblay \& Smith 2001). Reef fish trap catchability in Barbados was similarly negatively related to percent reef cover and substrate rugosity, suggesting that traps were more attractive to fish in areas of low habitat complexity (Robichaud et al. 2000). For reef fish in our study, it is unclear what mechanism or combination of mechanisms was driving higher detection rates on soft substrate, but possibilities include higher reef fish movement rates (Topping \& Szedlmayer 2011), larger or more persistent bait plumes (Tremblay \& Smith 2001), traps more likely to act as habitat or cover, or higher feeding motivation given low prey densities in soft-bottom habitats. Regardless, reef fish surveys should attempt to account for differences in detectability (or catchability) when sampling in different habitat types.

Other habitat characteristics besides percent hard bottom influenced the trap and video detection probabilities for some reef fish species. For instance, trap detectability of red porgy declined as the coverage of

\section{Influence of environmental conditions}

Water temperature also influenced trap detection probabilities of red porgy, gray triggerfish, and vermilion snapper. Given that fish are ectothermic, many studies have observed a positive relationship between catchability and water temperature when water temperature is low (e.g. Arreguín-Sánchez 1996), but feeding motivation and presumably catchability eventually decline when water temperature increases beyond the thermal niche of the species (Hayward \& Arnold 1996). Gray triggerfish and, to a lesser extent, vermilion snapper displayed a positive relationship between trap detectability and water temperature, whereas red porgy trap detectability was slightly negatively related to water temperature. These results suggest that gray triggerfish and vermilion snapper may have a thermal niche that is higher than that of red porgy. Moreover, of all species examined, gray triggerfish appear to be the most sensitive to changes in water temperature, while red snapper, whose binomial model excluded temperature, appear to be the least sensitive. 

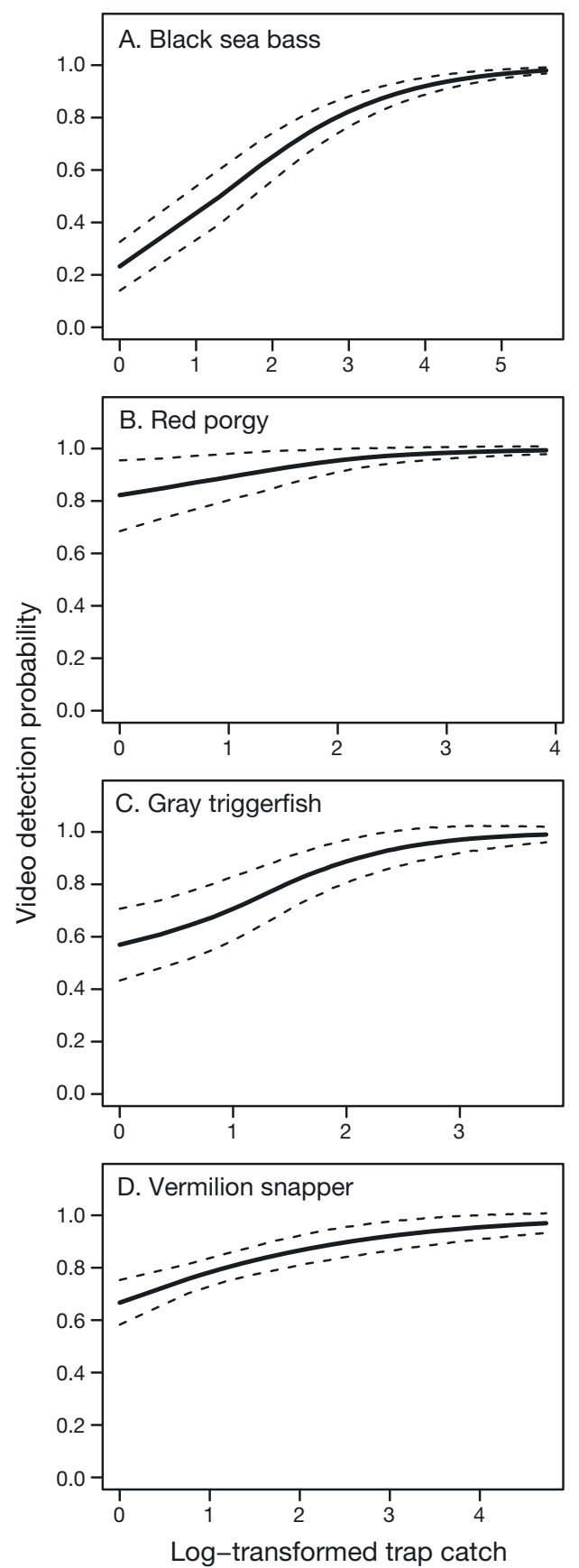

Fig. 7. Video detection probability of 4 reef fish species related to the log-transformed trap catch (i.e. index of site abundance) based from Southeast Reef Fish Survey trapvideo sampling. Solid lines are the predicted video detection probabilities, and dashed lines are $95 \%$ confidence intervals

Water clarity and current direction influenced the detectability of black sea bass, red porgy, and gray triggerfish on video. As hypothesized, video detection probabilities generally increased when water clarity was high. Although water clarity is generally acknowledged to be an important aspect of under- water video surveys (Mueller et al. 2006), we were unable to find any previous work that specifically related detectability or fish counts on video to water clarity levels. Interestingly, video detectability between high and moderate water-clarity levels was very similar, but declined substantially at low water clarity levels, suggesting that reef fish may be detected reasonably well as long as water clarity was above a modest threshold. Also as expected, video detection probabilities were lower when the current was moving towards, as opposed to away from, the camera, likely because most reef fish species tend to aggregate down-current of the trap to remain in the bait plume, similar to red king crabs Paralithodes camtschaticus (Zhou \& Shirley 1997). That trap detectability was influenced by current direction for only 1 of the 4 species examined (red porgy) suggests that current direction does not influence the trapping process as strongly as it does for video.

\section{Influence of site abundance}

Trap or video detection probabilities were positively related to the site-specific relative abundance for all species examined. Detection probability is often positively related to the abundance of the target organism (Royle \& Nichols 2003), but catch (or occupancy rates) can become decoupled from abundance for some gears, as has been shown for northern cod Gadus morhua in the northwest Atlantic (Shelton \& Lilly 2000). Reef fish trap catches have been shown to be correlated with video counts in the SEUS (Bacheler et al. 2013b), and trap catch has also tracked actual site abundance well for black sea bass (Bacheler et al. 2013a). While it is encouraging that detection probability and abundance were positively correlated for all reef fish species examined, the main reason for including trap catch or video MeanCount as predictor variables in our binomial models was to standardize detection probability for variable fish abundance at a site. We consider standardizing detection probability by site abundance to be a critical issue that must take place in future studies using similar methodological approaches as those presented here.

\section{Benefits and drawbacks of combining gears}

We estimated detection probabilities for reef fish using a multi-gear approach, where detection probabilities were estimated for one gear when confirmed 

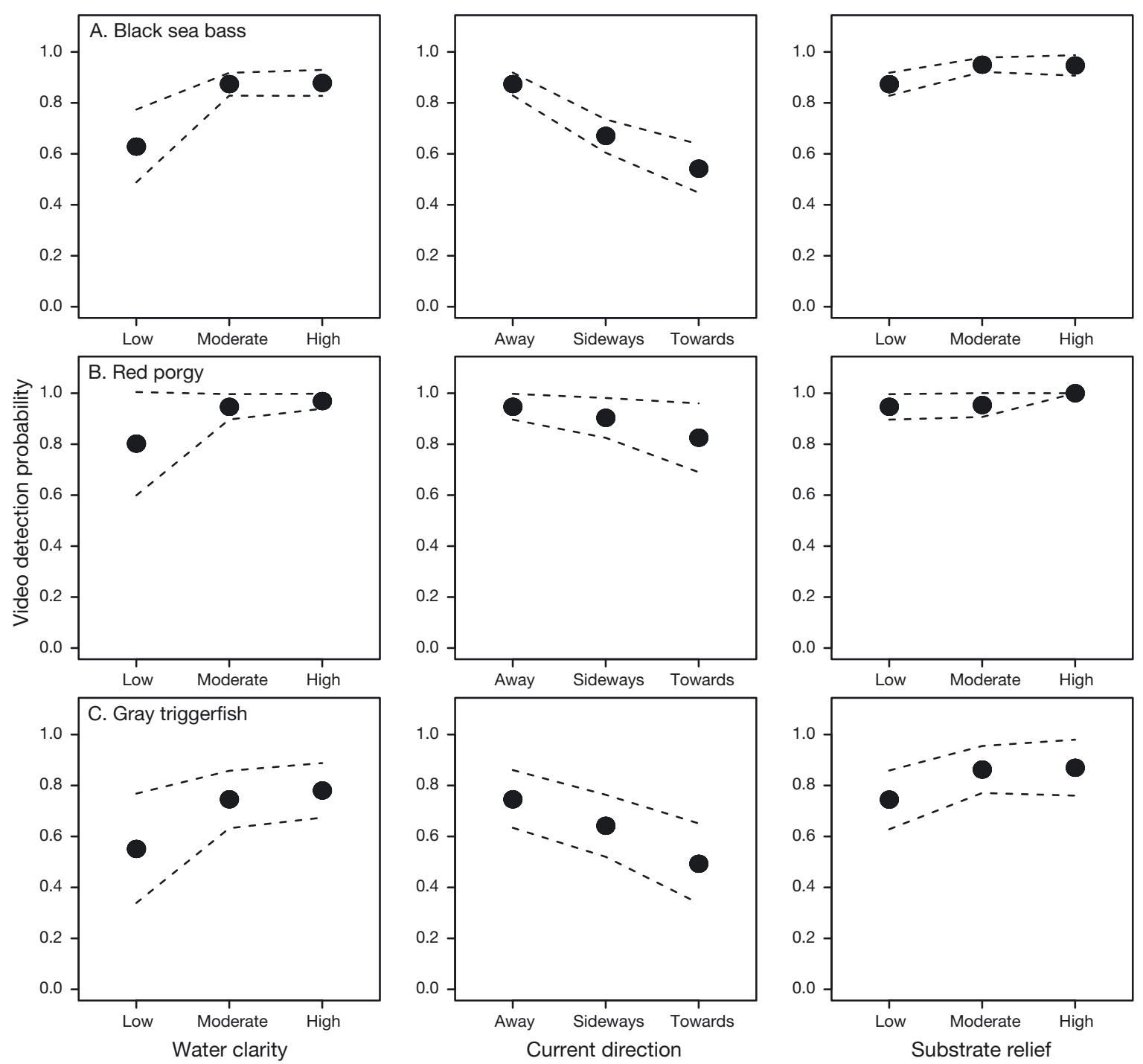

Fig. 8. Video detection probability of 3 reef fish species related to water clarity, current direction, or substrate relief from Southeast Reef Fish Survey trap-video sampling. Filled circles are the predicted video detection probabilities, and dashed lines are $95 \%$ confidence intervals

to be present at a site based on catches or counts from the corresponding gear. Few studies have used multiple gears to estimate detection probabilities; most studies use repeated site visits and assume that occupancy status within a sampling season remains unchanged among visits (MacKenzie et al. 2002). Multiple sampling gears have been used in some situations to expand detection probabilities and understand predictor variable effects for terrestrial (Graves et al. 2011) and aquatic organisms (Coggins et al. 2014). For example, Coggins et al. (2014) used trap and video data for red snapper in an occupancy modeling framework to show that depth and latitude influenced occupancy more than micro-habitat features, after accounting for imperfect detectability. Similar studies used the same sampling approach, such as observers or divers, at the same or very similar times to reduce or eliminate the temporal closure assumption (Issaris et al. 2012). We consider the use of multiple gears or observers to be superior to repeated site visits within a sampling season, both theoretically and empirically, because the potentially strong assumption of closure is not necessary. An approach with potential widespread appeal would be to add video cameras to other commonly used sampling gears such as trawls, acoustics, or nets to understand how detection probabilities of each gear are influenced by various predictor variables (e.g. Somerton et al. 1999).

There are some shortcomings of our methodological approach. First, only species caught in traps or 
seen on video many times, and with moderate detection probabilities, could be included in our binomial modeling analyses. Moreover, species whose models had the smallest samples sizes (i.e. red snapper in traps, vermilion snapper on video) also included the fewest significant predictors, suggesting that marginal sample sizes may have contributed to the low number of significant relationships. Second, our approach was able to determine how detection probabilities were influenced by predictor variables, but not how occupancy rates may have been influenced by those same factors. Last, detection probability on video could be increased by reading more snapshots or snapshots over a longer video interval (Bacheler \& Shertzer 2015).

These results underscore the importance of dealing with imperfect detectability in ecological research and monitoring surveys, especially in a highly dynamic coastal ecosystem like the SEUS that experiences significant variability in environmental conditions and contains different habitat types. Knowing how predictor variables influence the sampling process of various gears and gear-specific detection probabilities helps scientists design optimal surveys, especially for rare or elusive species. At the very least, indices of abundance should be standardized by the variables found to be important in this study (Maunder \& Punt 2004). More elegant and powerful approaches that should be considered in the future include occupancy models that specifically account for variation in abundance among sites (Royle \& Nichols 2003) or $N$-mixture models that actually use count data and are able to estimate individual capture probabilities (Royle 2004).

Acknowledgements. We thank the captains and crew of the RV 'Savannah,' RV 'Palmetto,' and NOAA Ship 'Pisces,' SERFS staff members, and numerous volunteers for making field work possible. We thank M. Burton, D. Glasgow, N. McNeil, D. Messinger, J. Ragland, and J. Vecchio for assisting with video reading. We benefited greatly from discussions with L. Coggins. We also thank A. Chester, L. Coggins, A. Hohn, T. Kellison, N. Klibansky, K. Purcell, and T. Smart for providing comments on earlier versions of this manuscript. Mention of trade names or commercial companies is for identification purposes only and does not imply endorsement by the National Marine Fisheries Service, NOAA.

\section{LITERATURE CITED}

Arreguín-Sánchez F (1996) Catchability: a key parameter for fish stock assessment. Rev Fish Biol Fish 6:221-242 Bacheler NM, Shertzer KW (2015) Estimating relative abundance and species richness from video surveys of reef fishes. Fish Bull 113 (in press)

Bacheler NM, Schobernd ZH, Berrane DJ, Schobernd CM,
Mitchell WA, Geraldi NR (2013a) When a trap is not a trap: converging entry and exit rates and their effect on trap saturation of black sea bass (Centropristis striata). ICES J Mar Sci 70:873-882

> Bacheler NM, Schobernd CM, Schobernd ZH, Mitchell WA, Berrane DJ, Kellison GT, Reichert MJM (2013b) Comparison of trap and underwater video gears for indexing reef fish presence and abundance in the southeast United States. Fish Res 143:81-88

> Bartolino V, Ciannelli L, Bacheler NM, Chan KS (2011) Ontogenetic and sex-specific differences in densitydependent habitat selection of a marine fish population. Ecology 92:189-200

Burnham KP, Anderson DR (2002) Model selection and multimodal inference: a practical information-theoretic approach, 2nd edn. Springer-Verlag, New York, NY

> Coggins LG, Bacheler NM, Gwinn DC (2014) Occupancy models for monitoring marine fish: a Bayesian hierarchical approach to model incomplete detection with a novel gear combination. PLoS ONE 9:e108302

Fry FEJ (1967) Responses of vertebrate poikilotherms to temperature. In: Rose AH (ed) Thermobiology. Academic Press, New York, NY, p 375-410

Geraldi NR, Wahle RA, Dunnington M (2009) Habitat effects on American lobster (Homarus americanus) movement and density: insights from georeferenced trap arrays, seabed mapping, and tagging. Can J Fish Aquat Sci 66: 460-470

Graves TA, Kendall KC, Royle JA, Stetz JB, Macleod AC (2011) Linking landscape characteristics to local grizzly bear abundance using multiple detection methods in a hierarchical model. Anim Conserv 14:652-664

> Green SJ, Tamburello N, Miller SE, Akins JL, Côté IM (2013) Habitat complexity and fish size affect the detection of Indo-Pacific lionfish on invaded coral reefs. Coral Reefs 32:413-421

> Halpern BS, McLeod KL, Rosenberg AA, Crowder LB (2008) Managing for cumulative impacts in ecosystem-based management through ocean zoning. Ocean Coast Manag 51:203-211

> Hangsleben MA, Allen MS, Gwinn DC (2013) Evaluation of electrofishing catch per unit effort for indexing fish abundance in Florida lakes. Trans Am Fish Soc 142:247-256

Hanski I (1999) Metapopulation ecology. Oxford University Press, Oxford

Hayward RS, Arnold E (1996) Temperature dependence on maximum daily consumption in white crappie: implications for fisheries management. Trans Am Fish Soc 125:132-138, doi:10.1577/1548-8659(1996)125<0132: TDOMDC $>2.3 . \mathrm{CO} ; 2$

Issaris Y, Katsanevakis S, Salomidi M, Tsiamis K, Katsiaras N, Verriopoulos G (2012) Occupancy estimation of marine species: dealing with imperfect detectability. Mar Ecol Prog Ser 453:95-106

- Katsanevakis S, Weber A, Pipitone C, Leopold M and others (2012) Monitoring marine populations and communities: methods dealing with imperfect detectability. Aquat Biol 16:31-52

Kendall MS, Bauer LJ, Jeffrey CFG (2008) Influence of benthic features and fishing pressure on size and distribution of three exploited reef fishes from the southeastern United States. Trans Am Fish Soc 137:1134-1146

> MacKenzie DI (2005) What are the issues with presenceabsence data for wildlife managers? J Wildl Manag 69: 849-860 
MacKenzie DI, Nichols JD, Lachman GB, Droege S, Royle JA, Langtimm CA (2002) Estimating site occupancy rates when detection probabilities are less than one. Ecology 83:2248-2255

MacKenzie DI, Nichols JD, Royle JA, Pollock KH, Bailey LL, Hines JE (2006) Occupancy estimation and modeling. Academic Press, San Diego, CA

Maunder MN, Punt AE (2004) Standardizing catch and effort data: a review of recent approaches. Fish Res 70: 141-159

Monk J (2014) How long should we ignore imperfect detection of species in the marine environment when modelling their distribution? Fish Fish 15:352-358.

Mueller RP, Brown RS, Hop H, Moulton L (2006) Video and acoustic camera techniques for studying fish under ice: a review and comparison. Rev Fish Biol Fish 16:213-226

Neter J, Wasserman W, Kutner MH (1989) Applied linear regression models, 2nd edn. Richard D. Irwin, Homewood, IL

NMFS (National Marine Fisheries Service) (2014) Fish Stock Sustainability Index. National Marine Fisheries Service, National Oceanic and Atmospheric Administration. Available at: www.nmfs.noaa.gov/sfa/fisheries_eco/ status_of_fisheries/ (accessed 19 May 2014)

Pollock KH, Nichols JD, Simons TR, Farnsworth GL, Bailey LL, Sauer JR (2002) Large scale wildlife monitoring studies: statistical methods for design and analysis. Environmetrics 13:105-119

Pollock KH, Marsh H, Bailey LL, Farnsworth GL, Simons TR, Alldredge MW (2004) Separating components of detection probability in abundance estimation: an overview with diverse examples. In: Thompson WL (ed) Sampling rare or elusive species: concepts, designs, and techniques for estimating population parameters. Island Press, Washington, DC, p 43-58

R Core Team (2014) R: a language and environment for statistical computing. R Foundation for Statistical Computing, Vienna. Available at: www.R-project.org (accessed 19 May 2014)

Reshetnikov AN, Ficetola GF (2011) Potential range of the invasive fish rotan (Perccottus glenii) in the Holarctic. Biol Invasions 13:2967-2980

Robichaud D, Hunte W, Chapman MR (2000) Factors affecting the catchability of reef fishes in Antillean fish traps. Bull Mar Sci 67:831-844

Editorial responsibility: Janet Ley, St. Petersburg, Florida, USA
Rota CT, Fletcher RJ, Dorazio RM, Betts MG (2009) Occupancy estimation and the closure assumption. J Appl Ecol 46:1173-1181

> Royle JA (2004) N-mixture models for estimating population size from spatially replicated counts. Biometrics 60: $108-115$

> Royle JA, Nichols JD (2003) Estimating abundance from repeated presence-absence data or point counts. Ecology 84:777-790

Schobernd CM, Sedberry GR (2009) Shelf-edge and upperslope reef fish assemblages in the South Atlantic Bight: habitat characteristics, spatial variation, and reproductive behavior. Bull Mar Sci 84:67-92

Schobernd ZH, Bacheler NM, Conn PB (2014) Examining the utility of alternative video monitoring metrics for indexing reef fish abundance. Can J Fish Aquat Sci 71: 464-471

Shelton PA, Lilly GR (2000) Interpreting the collapse of the northern cod stock from survey and catch data. Can J Fish Aquat Sci 57:2230-2239

Somerton D, Ianelli J, Walsh S, Smith S, Godø OR, Ramm D (1999) Incorporating experimentally derived estimates of survey trawl efficiency into the stock assessment process: a discussion. ICES J Mar Sci 56:299-302

Thompson WL (2004) Sampling rare or elusive species: concepts, designs, and techniques for estimating population parameters. Island Press, Washington, DC

> Topping DT, Szedlmayer ST (2011) Home range and movement patterns of red snapper (Lutjanus campechanus) on artificial reefs. Fish Res 112:77-84

Tremblay JM, Smith SJ (2001) Lobster (Homarus americanus) catchability in different habitats in late spring and early fall. Mar Freshw Res 52:1321-1331

Tyre AJ, Tenhumberg B, Field SA, Niejalke D, Parris K, Possingham HP (2003) Improving precision and reducing bias in biological surveys: estimating false-negative error rates. Ecol Appl 13:1790-1801

Wood SN (2006) Generalized additive models: an introduction with R. Chapman \& Hall/CRC, Boca Raton, FL

> Wood SN (2011) Fast stable restricted maximum likelihood and marginal likelihood estimation of semiparametric generalized linear models. J R Stat Soc B Stat Methodol 73:3-36

Zhou SJ, Shirley TC (1997) Behavioural responses of red king crabs to crab pots. Fish Res 30:177-189

Submitted: July 24, 2014; Accepted: October 23, 2014

Proofs received from author(s): December 4, 2014 